\title{
GRAPHICAL ANALYSIS AND EXPERIMENTAL DETERMINATION OF THE ACTIVE STATE IN FROG SKELETAL MUSCLE
}

\author{
Hidenobu Mashima, Kenzo Akazawa,* Hiroki Kushima, \\ and Katsuhiko FuJII* \\ Department of Physiology, School of Medicine, Juntendo University, Hongo, Tokyo \\ * Department of Electrical Engineering, Faculty of Engineering, \\ Osaka University, Osaka
}

\begin{abstract}
Summary 1) The time course of the active state was calculated by mathematical analysis based on the three-component model and compared with the experimental curve determined by quick release or stretch in the small bundle preparation dissected from frog semitendinosus muscle at $10^{\circ} \mathrm{C}$.

2) The three-component model contains a contractile component, which consists of a force generator and a viscous-like component, and a series elastic component. The active state as the force of the force generator is determined by substituting the tension and velocity curves of the contractile component for the force-load-velocity relation.

3) By this analytical method, the entire active state curve can be determined not only in the isometric but also in the isotonic contraction.

4) The active state of the isometric twitch does not reach its full extent of $P_{o}$ but only $0.7-0.8 P_{o}$.

5) In the isotonic contraction the duration of the active state decreases with decreasing load, and the rate of rise of the active state increases at the transition from isometric to isotonic contraction.

6) The active state curve determined by quick release or quick stretch agrees approximately with the curve determined by the analytical method when the amount of release or stretch is less than $2 \%$ of the muscle length, although the experimental curve varies with the amount of release or stretch.
\end{abstract}

Since the studies of HILL (1938) and WILKIE (1950), it has been generally considered that the skeletal muscle contains an active contractile component capable of generating tension in series with a noncontractile elastic component. On

Received for publication March 5, 1973

真島英信, 赤沢堅造, 九嶋宏樹, 藤井克彦 
stimulating the muscle, the contractile component is brought into an "active state," which is defined by HiLl (1949) as the tension developed when the contractile component is neither lengthening nor shortening. To determine the time course of the active state during a twitch, several experimental methods have been proposed. A first method described by Hill (1949) in frog sartorius muscle depends on quick stretch of the muscle at various times after stimulation. It was aimed primarily at determining the resistance to stretch or how quickly muscle reached its full capability for generating tension. A second method designed by RITCHIE (1954) is the quick-release method which concerns the peak of redeveloped twitch tension after a small amount of quick release at various times after stimulation. According to Hill's definition, the peak of tension curve coincides with the active state, because at the peak the change in tension with time is zero. This method, however, gave only the falling phase of the active state after the peak tension. A third method was described by Jewell and Wilkie (1960). They measured the velocity of isotonic shortening after the quick release. This gave almost the whole course of the active state, but there is some doubt about the idea that the capacity to shorten has the same physiological meaning as the capacity to develop tension.

Recently, BAHLER et al. (1967) presented a new analytical method for determining the whole course of the active state in rat gracilis anticus muscle. They defined the active state as a force-generating capability of the contractile component. The fact that the faster a muscle shortens the less force it exerts is interpreted as meaning that part of the force is dissipated internally as a function of the velocity, as though there were an internal load or viscous-like force. This analytical method is based on the three-component model which contains force generator, viscouslike component and series elastic component, as shown in Fig. 1. The active state curve was drawn as the sum of the isometric tension curve and the viscouslike force which was calculated from the force-velocity curve as the difference between the maximum force and the force exerted at each instance. This method has successfully been applied to frog cardiac muscle by MASHIMA and KusHima (1971).

In this paper, almost the same analytical method as Bahler's was employed, but definite difference depends on the force-velocity curve. While Bahler and his co-workers applied the simple force-velocity curve of fully activated muscle to a twitch, we used the force-load-velocity curves, which are a set of loadvelocity curves obtained not only on fully but also on partially activated muscle. The force-load-velocity relation has been described in a previous paper (MASHIMA et al., 1972). It must be emphasize that in the beginning of a twitch or during the relaxation the muscle is only partially activated.

\section{METHODS}

All the experiments were done on the small bundle (diameter, 500-800 $\mu$ ) 
of the fast muscle fibers prepared from the ventral caput of the semitendinosus muscle of Rana nigromaculata at $10^{\circ} \mathrm{C}$. The experimental arrangement and recording apparatus are similar to those described in the previous paper (MASHIMA et al., 1972). The muscle was mounted horizontally in a Ringer's solution bath $(3 \times 7 \times$ $1.5 \mathrm{~cm})$ between a pair of platinum foil electrodes $(7 \times 1.5 \mathrm{~cm})$ placed on the opposite walls of the bath. Thus, the whole length of the muscle was stimulated simultaneously by the transverse electric field created between these massive electrodes. Usually, 1-msec square pulses at $50-100 \mathrm{~Hz}$ or AC at $200-500 \mathrm{~Hz}$ were applied from a high-current stimulator. Composition of the Ringer's solution was as follows: $\mathrm{NaCl}=110, \mathrm{NaHCO}_{3}=12, \mathrm{KCl}=2, \mathrm{CaCl}_{2}=1.8$, all expressed in $\mathrm{mM}$, and $\mathrm{pH}$ was 7.2 .

The pelvic and tibial tendons were tied and attached to the isometric and isotonic levers, respectively. The tension and movement of the muscle were displayed simultaneously on a cathod ray tube (CRT). In order to make a quick release of the muscle, an electromagnetic relay to produce instantaneous withdrawal of a small hook was connected to the isotonic lever. When it was necessary to control the shortening or lengthening velocity of the muscle, the velocity controller designed by MASHIMA and MATSUMURA (1960) was connected to the isotonic lever. A quick stretch was made by a quick release of the lever with a sufficiently heavy load. The amount of quick release was set before stimulation by adjusting the position of a stop for the lever and measured on the enlarged photograph with an accuracy of $0.01 \mathrm{~mm}$.

The initial length of the preparation excluding tendons is always $L_{o}$, at which it can exert the maximum tension, $P_{o}$.

\section{RESULTS}

\section{Analytical method}

a) Mechanical model. It has been accepted that the mechanical behavior of the skeletal muscle can be described by a contractile component (CC) in series with a noncontractile series elastic component (SEC). Upon stimulation, the active state develops in the $\mathrm{CC}$, which generates force or shortens at the velocity obeying Hill's force-velocity relation (HILL, 1938). According to BAHLER et al. (1967), the force-velocity curve is characterized by the CC which develops a force, part of which is transmitted through the muscle so that it exerts tension, and part of which is dissipated internally as a function of the velocity with which the CC shortens. From these considerations a new mechanical model shown in Fig. 1 is proposed. In this three-component model, the contractile component consists of a force generator (FG) and a viscous-like component (VC). And the muscle tension as a function of time, $P(t)$, can be expressed by the difference between the force developed in the FG, $F(t)$, and the velocity-dependent tension-loss in the $\mathrm{VC}, F_{v}(t)$. Then we obtain, 


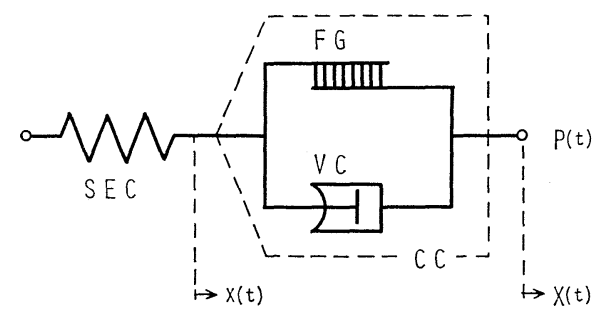

Fig. 1. Mechanical model of muscle. CC, contractile component; FG, force generator; VC, viscous-like component; SEC, series elastic component. $P(t)$, measured tension; $X(t)$, extension of the muscle; $x(t)$, extension of SEC.

$$
P(t)=F(t)-F_{v}(t)
$$

According to MASHIMA et al. (1972), $F_{v}(t)$ is a hyperbolic function of the velocity and at the same time it is a linear function of the force. It is reasonable to assume that $F(t)$ is nothing but the intensity of the active state which is defined by HILL (1949) as the intrinsic strength of the contractile component, because $F(t)$ is a time course of the force-generating capability of the contractile component. Then, the active state can be determined from $P(t)$ and $F_{v}(t)$, which can be obtained from the force-load-velocity relation of $\mathrm{CC}$ and the tension-extension reslation of SEC when $P(t)$ is given. However, it is necessary to obtain these relations in the same muscle and under the same conditions.

b) Force-load-velocity relation of the contractile component. In the previous paper (MASHIMA et al., 1972), Hill's force-velocity equation,

$$
(P+a)(v+b)=b\left(P_{o}+a\right)
$$

was generalized to the following force-load-velocity equation,

$$
\begin{aligned}
& (P+A)(v+b)=b(F+A) \quad(v \geqq 0) \\
& A=a\left(F / P_{\circ}\right)
\end{aligned}
$$

where $P$ is the load or the force during isotonic contraction, $F$ is the intensity of the active state or the force during isometric contraction, $v$ is the shortening velocity of the contractile component, $P_{o}$ is the maximum isometric force, $a$ is the heat constant and $b$ is the rate constant of energy liberation. The value of $a / P_{o}$ was 0.25 and $b / L_{o}$ was $0.9 \mathrm{sec}^{-1}$ in our preparation at $10^{\circ} \mathrm{C}$.

When the muscle was lengthened by a load heavier than the developed force, the relation was also described by a hyperbolic equation,

$$
\begin{aligned}
& \left(P-2 F-A^{\prime}\right)\left(v-b^{\prime}\right)=b^{\prime}\left(F+A^{\prime}\right) \quad(v<0) \\
& A^{\prime}=a^{\prime}\left(F / P_{o}\right)
\end{aligned}
$$

The value of $a^{\prime} / P_{o}$ was 0.4 and $b^{\prime} / L_{o}$ was $0.85 \mathrm{sec}^{-1}$ at $10^{\circ} \mathrm{C}$. These results were used in this paper (see Fig. 4D). 
c) Tension-extension relation of the series elastic component. The tensionextension curve of SEC was directly determined by the controlled quick-release method using the velocity controller. In order to improve the accuracy of the measurement for the amount of quick shortening of SEC, it was necessary to decrease the mechanical oscillation which appeared immediately after the quick release of the isotonic lever. For this purpose we used the velocity controller and confined the velocity of the quick shortening after the release until the overshoot of the shortening curve was minimized, while Jewell and WILKIE (1958) attached a small dashpot containing castor oil to the lever. The tension-extension curve thus obtained is shown in Fig. 2. Curve A was obtained from the prepara-

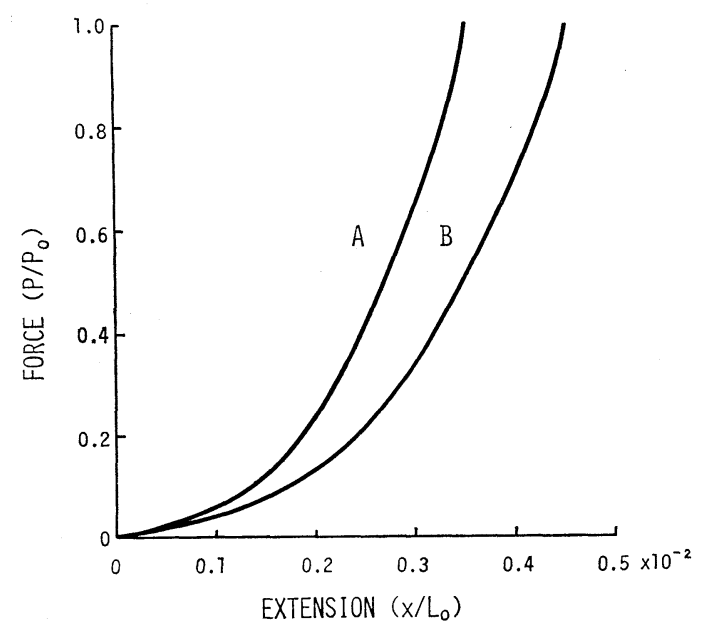

Fig. 2. Tension-extension curve of SEC. A, short tendon preparation; B, long tendon preparation.

tion with short tendons, in which the pelvic and tibial tendons were tied near the end of muscle fibers in order to make the tendons as short as possible. On the other hand, curve B was obtained from the long tendon preparation, both tendons of which were tied near the bones. Usually each tendon was 1-2 $\mathrm{mm}$ long in the long tendon preparation. In the short tendon preparation the extension of SEC was about $3.5 \% L_{o}$ at the tension of $P_{o}$ but it was $4.5 \% L_{o}$ in the long tendon preparation. Obviously, the compliance of the preparation depends on the length of tendon.

Although SANDOw (1958) employed an exponential equation as the experimental formula of the tension-extension curve, we approximated this with a third-power equation to facilitate computer calculation. We obtain

$$
\begin{aligned}
& P=K_{s} x \\
& K_{s}=\left(2.9+51.8 \hat{x}+1.9 \times 10^{4} \hat{x}^{2}\right) P_{o} / L_{o}
\end{aligned}
$$


where $P$ is the tension, $x$ is the extension, $\hat{x}$ is the normalized value of $x\left(\hat{x}=x / L_{o}\right)$ and $K_{s}$ is the elastic coefficient.

d) Mathematical formulation. The active state curve, $F(t)$, can be obtained from the force-load-velocity relation of CC expressed by eqs. (2) and (3) and the

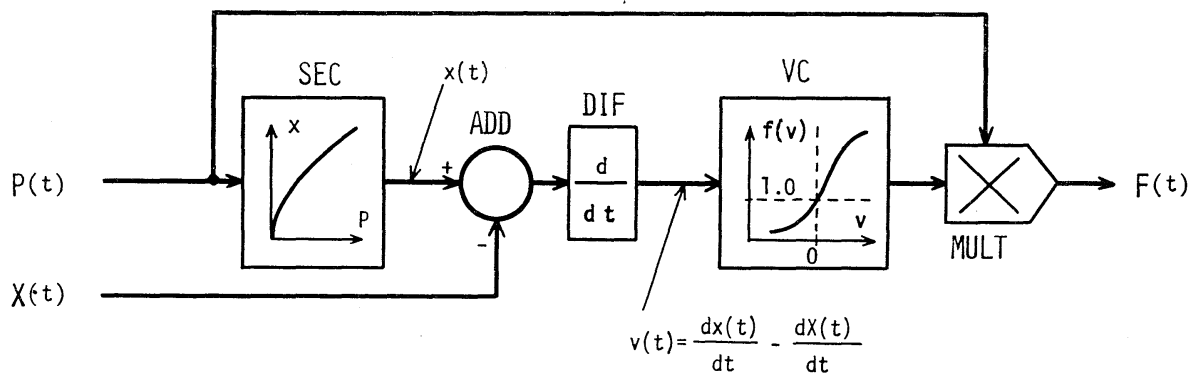

Fig. 3. Blockdiagram for computer calculation of the active state curve, $F(t)$, from tension curve, $P(t)$, and shortening curve, $X(t)$. SEC, function element generating the tensionextension $(P-x)$ relation of SEC, (input, $P$; output, $x$ ); VC, function element generating the $v-f(v)$ relation of $\mathrm{VC}$, (input, $v$; output, $f(v)$ ); ADD, adder; DIF, differentiator; MULT, multiplier.

tension-extension relation of SEC expressed by eq. (4), when the tension curve, $P(t)$, and the shortening curve of muscle, $-X(t)$, during the contraction are given.

Rearranging eqs. (2) and (3), we obtain

$$
\begin{array}{rlrl}
F & =f(v) P & \\
f(v) & =\frac{b+v}{b-\frac{a}{P_{o}} v} & & (v \geqq 0) \\
f(v) & =\frac{b^{\prime}-v}{b^{\prime}-\left(2+\frac{a^{\prime}}{P_{0}}\right) v} & & (v<0)
\end{array}
$$

$F, P$ and $v$ are functions of time. And the velocity of $\mathrm{CC}$ as a function of time, $v(t)$, can be obtained from the equation,

$$
v(t)=\frac{d x(t)}{d t}-\frac{d X(t)}{d t}
$$

where $x(t)$ is the extension of SEC and $X(t)$ is the extension of muscle as a function of time. If $P(t)$ is given, $x(t)$ can be calculated from eq. (4). Finally, $F(t)$ can be obtained from the tension curve, $P(t)$, and the extension curve of muscle, $X(t)$. The blockdiagram for computer calculation of the above-described formula is shown in Fig. 3. If $P(t)$ and $X(t)$ are measured simultaneously, this analytical method to determine the active state curve is applicable not only to the isometric but also to the isotonic or any other type of contraction. 
On the other hand, from eq. (1) the viscous-like force is

$$
F_{v}(t)=F(t)-P(t)
$$

Therefore, $F_{v}(t)$ can be obtained from $P(t)$ and $F(t)$. Furthermore, substituting eqs. (5)-(7) for eq. (9), $F_{v}$ can also be expressed as a function of $v$ and $P$.

$$
\left.\begin{array}{ll}
F_{v}=\frac{\left(P_{o}+a\right) v}{P_{o} b-a v} P & (v \geqq 0) \\
F_{v}=\frac{\left(P_{0}+a^{\prime}\right) v}{P_{o} b^{\prime}-\left(2 P_{o}+a^{\prime}\right) v} P & (v<0)
\end{array}\right\}
$$

\section{Determination of the active state during isometric twitch}

The time course of the active state, $F(t)$, was determined from the tension curve, $P(t)$, by the analytical method, that is, computer calculation or graphical analysis. The procedure of graphical analysis is illustrated in Fig. 4 on the isometric twitch of the short tendon preparation. In Fig. 4A, the tension curve, $P(t)$, at $L_{o}$ is traced. As shown in Fig. 4B the time course of the lengthening of SEC, $x(t)$, is obtained by converting $P(t)$ through the tension-extension curve of SEC, which is the trace of Fig. 2A. The curve $x(t)$ thus obtained is shown in Fig. 4C. In the isometric contraction, $X(t)$ is zero and the amount of the lengthening of SEC is equal to that of the shortening of $\mathrm{CC}$. Then, the time course of shortening velocity of CC, $v(t)$, is the differential of $x(t)$, i.e. $d x(t) / d t$, which is also shown in Fig. 4C. The time course of $f(v)$ in eq. (6) or (7) is obtained by converting the curve $v(t)$ through the $v-f(v)$ curve which is seen in Fig. 4D. During the relaxation $v(t)$ has minus sign, because the $\mathrm{CC}$ is lengthened, so that the $v-f(v)$ curve in the third quardrant of Fig. 4D is used. The curve $f(v)$ thus obtained is shown in Fig. 4E. Finally, the active state curve, $F(t)$, can be drawn by the relation of eq. (5) as the product of $P(t)$ and $f(v)$, as illustrated in Fig. 4A. The viscous-like force curve, $F_{v}(t)$, is also drawn by using the relation of eq. (9) as the difference between $F(t)$ and $P(t)$, as also illustrated in Fig. 4A. With the long tendon preparation, the active state curve is also determined as shown in Fig. 5 by the same procedure, using the curve B in Fig. 2 as the tension-extension curve of SEC. In both preparations $F(t)$ curve does not attain the full extent of $P_{o}$ and no plateau appears during the isometric twitch. The peak value of $F(t)$ is about $0.7 P_{o}$ in the short tendon preparation and $0.8 P_{o}$ even in the long tendon preparation. The reason for this result may be explained by the fact that the long tendon preparation is more compliant and the rate of rise of tension is faster than that of the short one.

The time course of the active state developed by repetitive stimuli was also drawn by the same procedure. One of the results is shown in Fig. 6, where the square pulses at $100 \mathrm{~Hz}$, which corresponds to the critical fusion frequency at $10^{\circ} \mathrm{C}$, are applied. The curves in Fig. $6 P$ are the isometric tension curves generated by $1,2,3,4,6$ and 10 pulses. The active state curves of these contractions 


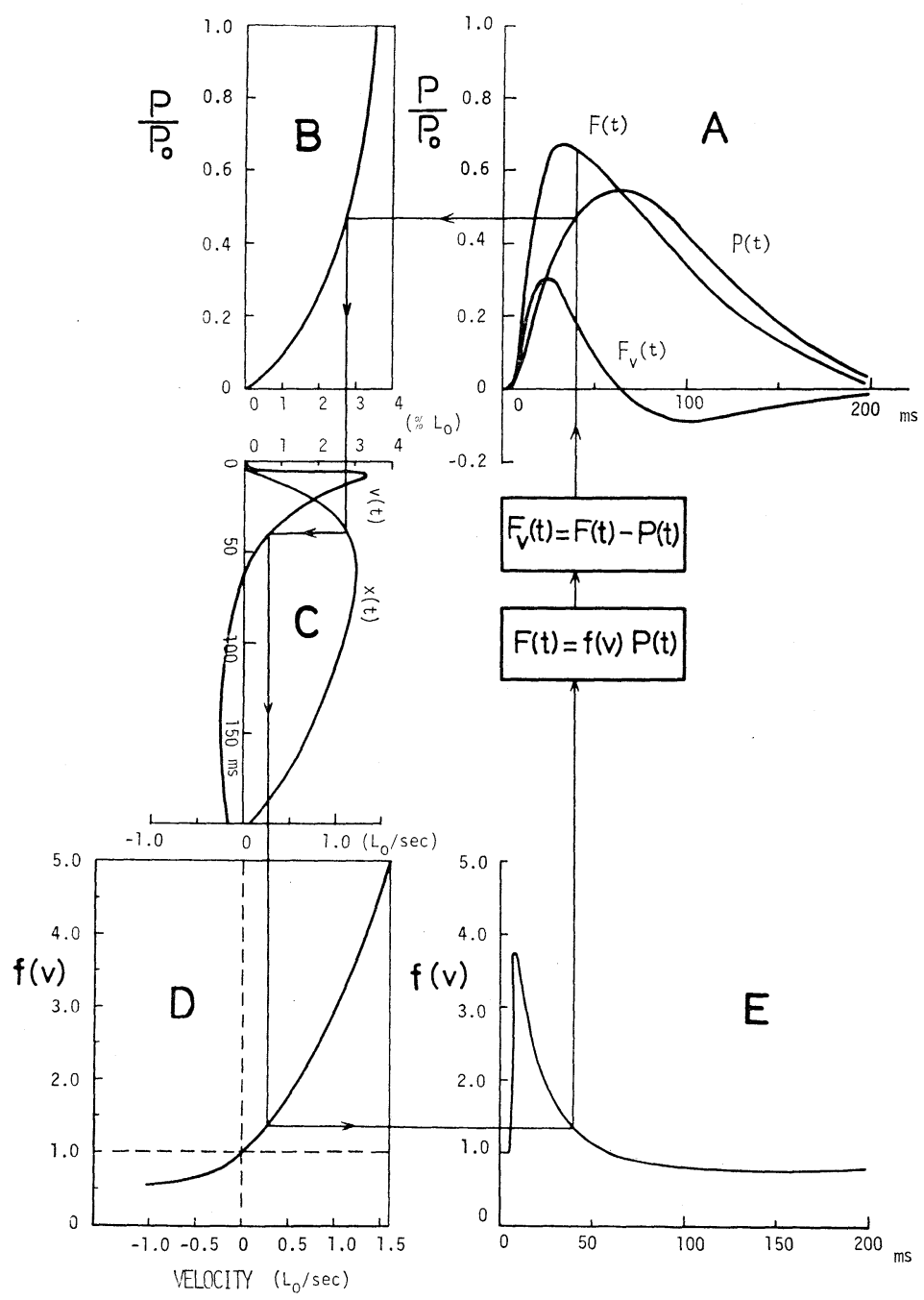

Fig. 4. Graphical analysis of the active state curve during isometric twitch of short tendon preparation. A, tension curve, $P(t)$, active state curve, $F(t)$, and viscous-like force curve, $F_{v}(t) ; F(t)=P(t)+F_{v}(t)$; B, tension-extension curve of SEC; C, lengthening curve of SEC, $x(t)$, and velocity of CC, $v(t)=d x(t) / d t ; \mathrm{D}, v-f(v)$ curve of VC; $\mathrm{E}, f(v)$ curve; ms, msec. Arrows indicate the order of procedure.

are shown in the lower part of Fig. 6. Generally, 2 or 3 pulses were necessary for the summated active state to reach the full intensity of $P_{o}$. When more pulses are applied the plateau is maintained at the level of $P_{0}$. In particular, the plateau duration at more than 6 pulses is prolonged every pulse by the amount of pulse interval. The half time of the rising phase of the active state is about $20 \mathrm{msec}$ independently of the number of pulses. The half time of the falling phase increases 


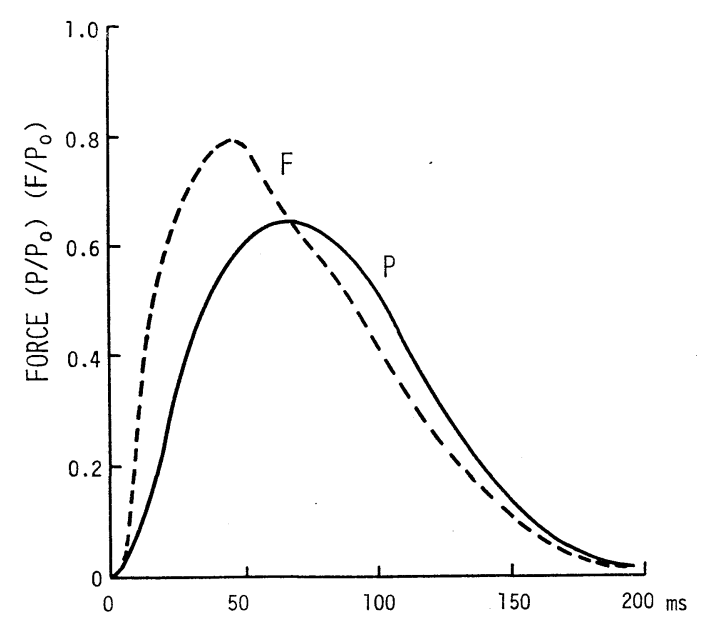

Fig. 5. The active state curve during isometric twitch of long tendon preparation. $P$, tension curve; $F$, active state curve determined by graphical analysis; $P_{o}=3.7 \mathrm{~g} ; L_{o}=$ $14 \mathrm{~mm}$; $\mathrm{ms}, \mathrm{msec}, 10^{\circ} \mathrm{C}$.

with increasing number of pulses, for example in Fig. 6, about $60 \mathrm{msec}$ at a single pulse, $75 \mathrm{msec}$ at 2 pulses and $125 \mathrm{msec}$ at 3 pulses, but no more increase is observed at more than 3 pulses.

As shown in Figs. 4 and 5, the time to peak of the active state is about $40 \mathrm{msec}$ in the isometric twitch of the short tendon preparation, while it is about $50 \mathrm{msec}$ in the long tendon preparation. The time to plateau of the active state in the isometric tetanus is also about $40 \mathrm{msec}$ as seen in Fig. 6, point B.

If the active state reaches its full activity during a twitch, the $P-v$ relation at that time should satisfy the load-velocity relation at $F=P_{o}$. Whether the active state really reached full activity or not was checked in the following way. Curve 1.0 in Fig. 7 shows the load-velocity curve at $F=P_{o}$ which was obtained by substituting $F=1.0 P_{o}$ for eqs. (2) and (3). Curve a is the Lissajous' figure showing the relation between the muscle tension, $P(t)$, and the velocity of $\mathrm{CC}$, $v(t)$, during the isometric twitch in Fig. 6. Apparently, curve a does not intersect curve 1.0. This means that the full active state is never attained at any instance during the twitch. On the other hand, curve $\mathrm{b}$ in Fig. 7 is the $P-v$ Lissajous' curve during the 10-pulse tetanic contraction in Fig. 6. This curve coincides with curve 1.0 between points $\mathrm{B}$ and $\mathrm{C}$, that is, the active state was maintained at full extent of $1.0 P_{o}$ during the period between $B$ and $C$, which is about 40 to $150 \mathrm{msec}$ after the first stimulus. Points $\mathrm{B}$ and $\mathrm{C}$ in Fig. 7 correspond to points $\mathrm{B}$ and $\mathrm{C}$ in Fig. 6, respectively.

Furthermore, curve 0.5 in Fig. 7 is the load-velocity curve at $F=0.5 P_{o}$, which was obtained by substituting $F=0.5 P_{o}$ for eqs. (2) and (3). This curve intersects curve a at $\mathrm{A}$ and $\mathrm{D}$, and curve $\mathrm{b}$ at $\mathrm{E}$ and $\mathrm{F}$. Therefore, at the instants 


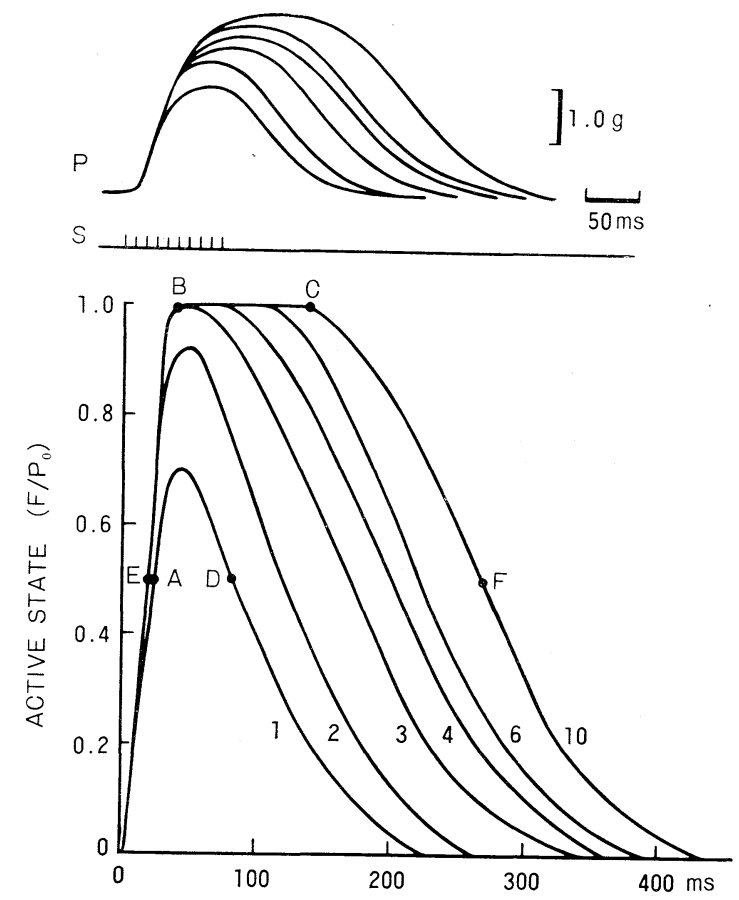

Fig. 6. Effect of the number of stimuli on the active state curve of isometric contraction (short tendon preparation). Upper, $P$, isometric tension curves generated by $1,2,3,4$, 6 and 10 pulses at the interval of $10 \mathrm{msec} ; S$, stimuli; Lower, active state curve determined by graphical analysis; curve 1, 2, 3, 4, 6 and 10 are generated by 1, 2, 3, 4, 6 and 10 pulses respectively. The instants $\mathrm{A}, \mathrm{B}, \mathrm{C}, \mathrm{D}, \mathrm{E}$ and $\mathrm{F}$ correspond to $\mathrm{A}, \mathrm{B}, \mathrm{C}, \mathrm{D}, \mathrm{E}$ and $\mathrm{F}$ in Fig. 7 respectively. $\mathrm{ms}, \mathrm{msec} ; 10^{\circ} \mathrm{C}$.

corresponding to these points, the intensity of the active state is $0.5 P_{o}$. The points A, D, E and F in Fig. 7 correspond to A, D, E and F in Fig. 6, which are the instants after $21,75,21$ and $270 \mathrm{msec}$ from the start of stimulation, respectively.

\section{Determination of the active state during isotonic twitch}

According to MASHIMA et al. (1972), the force-load-velocity relation was valid even when the muscle length was changed between 0.8 and $1.2 L_{0}$. Therefore, the analytical method described above is applicable to determining $F(t)$ curve of the isotonic contraction during which the muscle length is changing, provided that the tension curve, $P(t)$, and the shortening curve, $-X(t)$, are given. For example, Fig. $8 \mathrm{~A}$ and $\mathrm{B}$ are the tension and shortening curves of the after-load twitches against various after-loads. While the initial length was always kept at the slack length of $L_{o}$ by the stop for the isotonic lever, the pre-load was zero. Curve a is the isometric twitch, and curves $\mathrm{b}, \mathrm{c}$ and $\mathrm{d}$ are the after-load twitches against the load of $0.9 \mathrm{~g}, 0.45 \mathrm{~g}$ and $0.2 \mathrm{~g}$, respectively. 


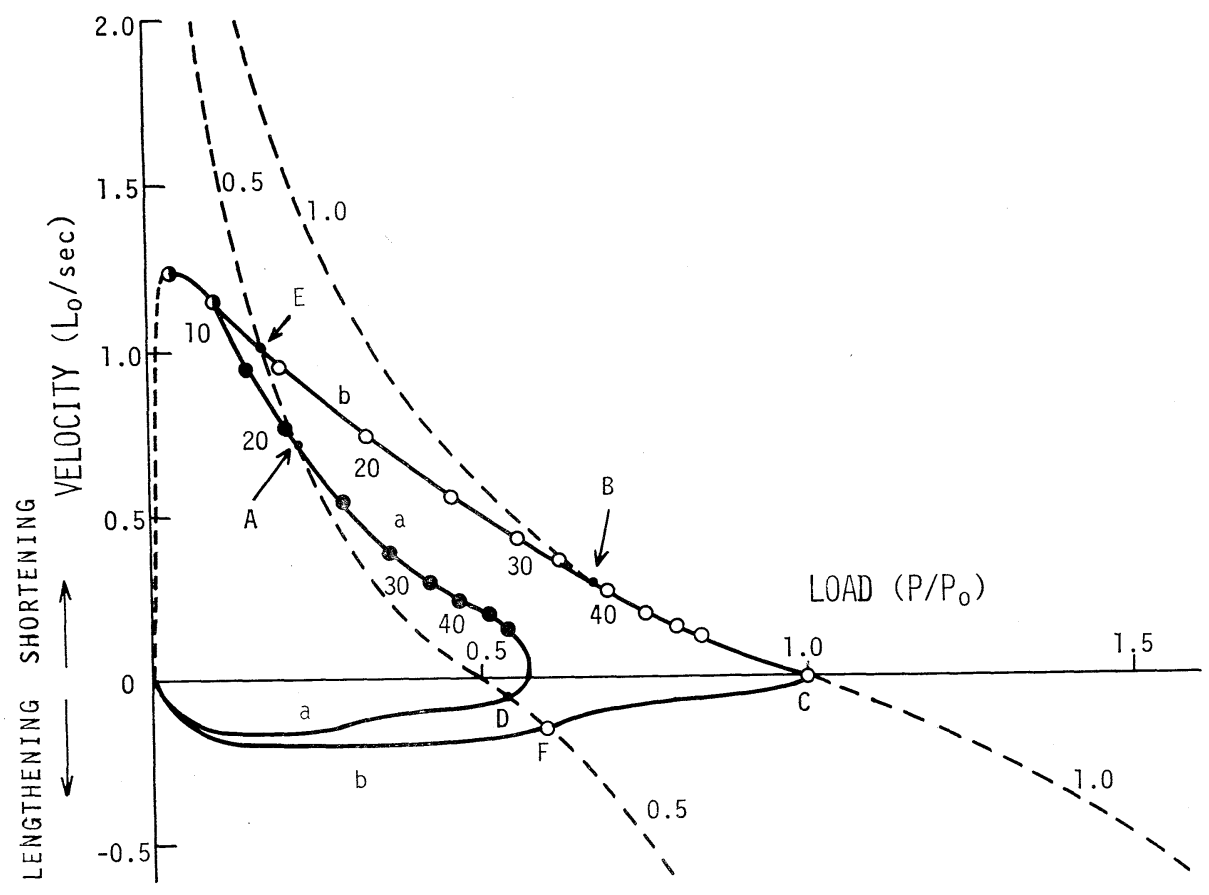

Fig. 7. Force-velocity relation during the twitch (filled circle, curve a) and tetanus (open circle, curve b). Dotted lines 0.5 and 1.0 are $P-v$ curves at $F=0.5 P_{o}$ and $F=1.0 P_{o}$, respectively. Number under the circle represents the time after the first stimulus. A, B, C, D, E and F show the instants of A, B, C, D, E and F in Fig. 6 respectively.

Firstly, the extension of SEC, $x(t)$, was obtained from $P(t)$ through the tension-extension curve of SEC. Secondly, the velocity of CC, $v(t)$, was calculated from eq. (8), using $x(t)$ and $X(t)$. Finally, the active state curve $F(t)$ was calculated from eqs. (5)-(7). The active state curves thus obtained are shown in Fig. 8C. Apparently, the time course of the active state varies with load, especially in duration. With a decrease in the load, the duration, time to peak and peak intensity clearly decrease. All of them are largest under the isometric condition. Although the rate of rise or fall of the active state is almost unchanged, the rate of rise increases slightly at the transition from isometric to isotonic contraction.

\section{Instantaneous recording of the active state with isometric tension curve}

Instead of the graphical analysis described above, of course, it is possible to record the active state curve of the isometric contraction simultaneously with the tension curve, using an ON-LINE computer which operates the electronic circuit shown in Fig. 3. But this procedure is too complicated for practical use, because the circuit contains two variable function elements and a multiplier. Therefore, we assumed that the elastic coefficient of SEC, $K$, is a constant which 

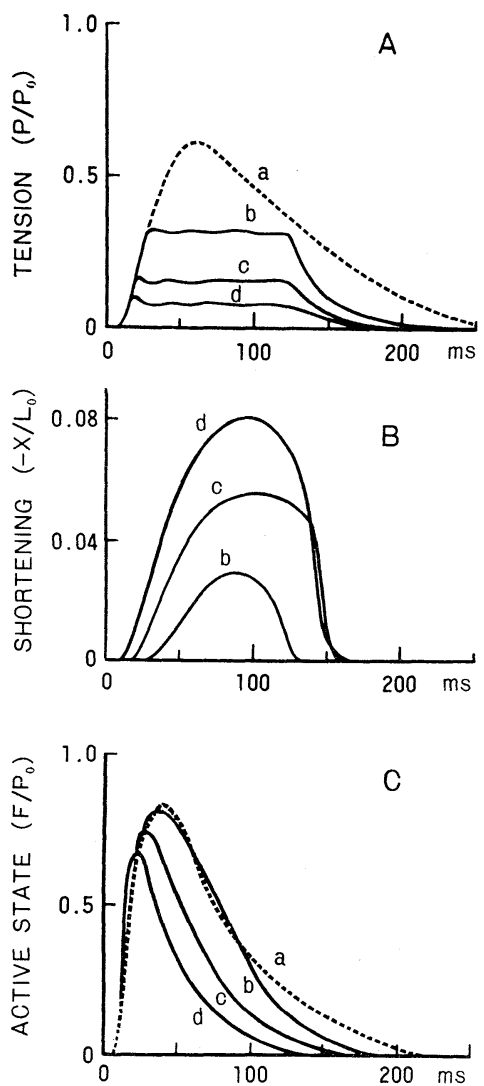

Fig. 8. The active state curve during isotonic contraction determined by graphical analysis. A, tension curve; $\mathrm{B}$, shortening curve; $\mathrm{C}$, active state curve; a, isometric twitch; b, c, d, isotonic twitch (after-load: b, $0.2 \mathrm{~g} ; \mathrm{c}, 0.45 \mathrm{~g} ; \mathrm{d}, 0.9 \mathrm{~g}$ ); $P$, tension; $-X$ shortening of muscle; $F$, active state. $P_{o}=3.0 \mathrm{~g} ; L_{o}=14 \mathrm{~mm} ; \mathrm{ms}, \mathrm{msec} ; 10^{\circ} \mathrm{C}$.

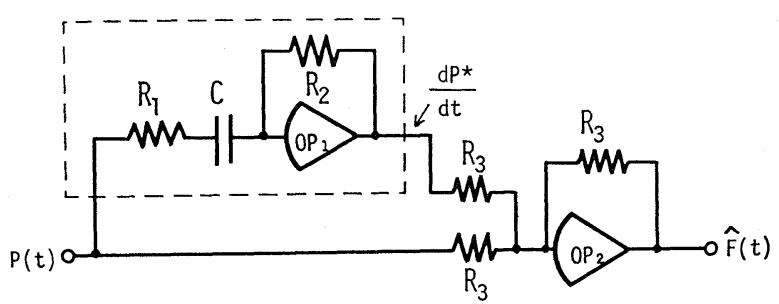

Fig. 9. Operational circuit for calculating the approximated active state curve, $\hat{F}(t)$, during isometric contraction. $\hat{F}(t)=P(t)+d P^{*} / d t$ (sec eq. (14)); $\mathrm{OP}_{1}$ and $\mathrm{OP}_{2}$, linear operational amplifiers. 
is independent of tension and that the viscous coefficient of $\mathrm{VC}, B$, is a constant which is independent of force or velocity, because the displacement of CC is sufficiently small in an isometric contraction and the viscosity would be a linear function of velocity as the first approximation. Then, we obtain the following equation instead of eq. (4),

$$
P(t)=K x(t)
$$

and also obtain instead of eq. (1),

$$
P(t)=\hat{F}(t)-B \frac{d x(t)}{d t}
$$

Then we obtain

$$
\begin{aligned}
\hat{F}(t) & =P(t)+k \frac{d P(t)}{d t} \\
k & =B / K
\end{aligned}
$$

where $\hat{F}(t)$ is the approximate value of $F(t)$. From eq. (13), $\hat{F}(t)$ can be obtained as the sum of the isometric tension curve, $P(t)$, and its differential curve, $d P(t) / d t$. These calculations can easily be made by a more simplified circuit, containing only linear operational amplifiers as shown in Fig. 9. Thus, an instantaneous recording of the active state becomes far easier. Theoretically, a complete differential operation can be made when $R_{1}$ in Fig. 9 is zero. If so, however, the circuit would become unstable because of the overload for the amplifier. Therefore, the approximate differential circuit seen in Fig. 9 (broken line) was used for practical application. The transfer function of the circuit is $k s /(1+\tau s)$, where $k=\mathrm{CR}_{2}$, $\tau=\mathrm{CR}_{1}$ and the symbol $s$ represents Laplace transform variable. If the time constant, $\tau$, is set to be sufficiently small compared with that of tension response, the differential operation is accurate enough, at least for practical use. Finally, the approximate calculation is expressed by the following equation instead of eq. (13),

$$
\begin{aligned}
\hat{F}(t) & =P(t)+\frac{d P(t)^{*}}{d t} \\
\frac{d P(t)^{*}}{d t} & =L^{-1}\left[\frac{k s}{1+\tau S} P(s)\right]
\end{aligned}
$$

where the symbol $L^{-1}[G(s)]$ denotes inverse Laplace transform of $G(s)$, and $P(s)$ is the Laplace transform of $P(t)$.

In order to operate this circuit, the time constants, $k$ and $\tau$, have to be determined. In frog ventricle, it has been confirmed experimentally by MASHIMA and Kushima (1971) that the value of $k$ is almost unchanged with the change in muscle length, taking the nonlinearity of SEC and VC into consideration, and the value of $k$ is $0.05-0.056 \mathrm{sec}$ at $20^{\circ} \mathrm{C}$. But in the skeletal muscle, it is impossible to estimate theoretically or experimentally this value of $k$, because of the complicated 
A

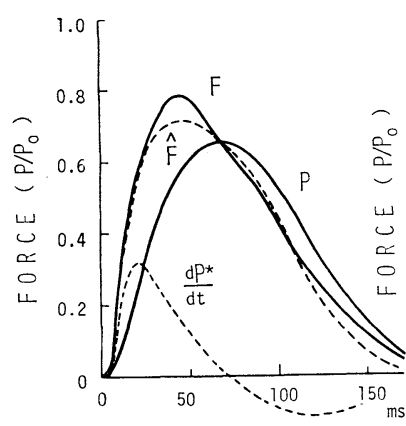

B

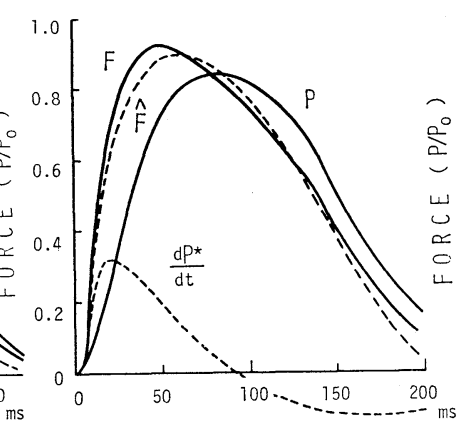

C

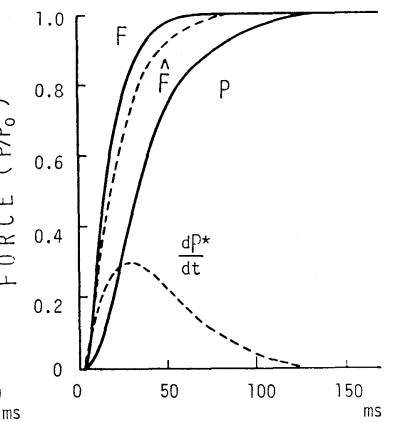

Fig. 10. Comparison of the approximated curve $(\hat{F})$ with the active state curve determined by graphical analysis $(F) . \quad \hat{F}=P+d P^{*} / d t ; P$, measured isometric tension curve; A, single pulse; $\mathrm{B}, 2$ pulses; C, 16-pulse stimulation; stimulus interval, $12.5 \mathrm{msec}$; ms, msec; $10^{\circ} \mathrm{C}$.
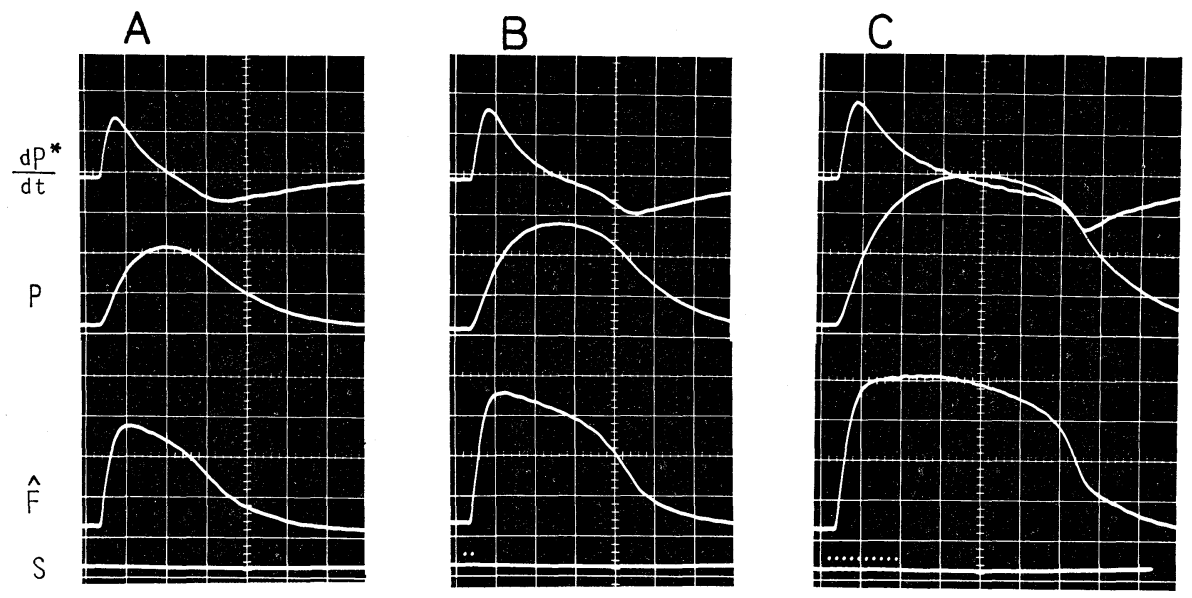

Fig. 11. Simultaneous recording of isometric tension $(P), d P^{*} / d t$ and $\hat{F}\left(=P+d P^{*} / d t\right)$ curves. A, single pulse; B, 2 pulses; C, 10-pulse stimulation; stimulus interval, $10 \mathrm{msec}$; ordinate, $2.0 \mathrm{~g} / \mathrm{div}$; sweep, $50 \mathrm{msec} / \mathrm{div} ; S$, stimulus; long tendon preparation; $L_{o}=$ $14 \mathrm{~mm} ; 10^{\circ} \mathrm{C}$.

nonlinearity of VC. Therefore, the values of $k$ and $\tau$ were estimated by trial and error so as to let $\hat{F}(t)$ coincide closely with the active state curve determined by the graphical analysis. Eventually, best fit was obtained when $k=17.0 \mathrm{msec}$ and $\tau=4.2 \mathrm{msec}$ in our preparation at $10^{\circ} \mathrm{C}$. One of the results of computer calculation in the long tendon preparation is shown in Fig. 10. Figure 10A represents the isometric twitch, Figs. B and $\mathrm{C}$ the isometric contractions by 2 and 16 pulses with the interval of $12.5 \mathrm{msec}$, respectively. Curve $P$ is the measured tension curve, curve $F$ is the active state curve determined by graphical analysis and curve 
$\hat{F}$ is the approximated curve obtained from eq. (14). The $\hat{F}(t)$ curve shows fairly good coincidence with the $F(t)$ curve in these isometric contractions, when the above-mentioned time constants are employed.

On materialization of the circuit shown in Fig. 9, the values of $k=17.0 \mathrm{msec}$ and $\tau=4.2 \mathrm{msec}$ were selected, for example, by setting $\mathrm{C}=1.0 \mu \mathrm{F}, \mathrm{R}_{1}=4.2 \mathrm{k} \Omega$ and $R_{2}=17.0 \mathrm{k} \Omega$. But even if the value of $R_{1}$ is not accurately $4.2 \mathrm{k} \Omega$ but, for example, $5.0 \mathrm{k} \Omega$, there would be very little effect on $\hat{F}(t)$. Moreover, on inspection of Fig. 4 or 10 , it is seen that the peak value of $F_{v}(t)$ is about half that of $P(t)$ in an isometric twitch. Therefore, it is not necessary to look for the most adequate value of $R_{2}$ by the trial and error method described above, rather it is far more practical to adjust the gain of differential circuit in the following way. Firstly, $P(t)$ and $d P / d t$ curves of isometric twitch are displayed simultaneously on a CRT. Secondly, the gain of the amplifier for $d P / d t$, that is, the value of $\mathrm{R}_{2}$, is adjusted until the maximum amplitude of $d P / d t$ becomes about half that of $P(t)$. In this way, $P(t), d P / d t$ and $\hat{F}(t)$ curves were recorded simultaneously as shown in Fig. 11. Another piece of evidence which may verify this conventional way is the fact that the plateau phase in the $\hat{F}(t)$ curve of isometric tetanus was completely smoothed at the level of $P_{o}$ as shown in Fig. $11 \mathrm{C}$, when the maximum $d P / d t$ of the twitch was adjusted so as to be about half the maximum $P(t)$ of the twitch as seen in Fig. 11A. If the gain of $d P / d t$ is raised higher than that, a spike-like hump higher than $P_{o}$ appears in the initial phase of $\hat{F}(t)$ curve of the tetanus.

\section{Experimental determination of the active state}

a) Quick-release method. The active state after the peak of isometric curve was determined experimentally by the quick-release method devised by RITCHIE (1954), and it was compared with the active state curve determined by graphical analysis. According to JeWELL and WILKIE (1960), Ritchie's method might underestimate the duration of the active state, but it was possible to reduce this error by decreasing the amount of quick release; for example, in the frog sartorius muscle when the release was $1.6 \% L_{o}\left(L_{o}=31 \mathrm{~mm}\right.$, amount of release $\left.=0.5 \mathrm{~mm}, 0^{\circ} \mathrm{C}\right)$, the measured active state curve almost coincided with the correct one. In the present study, the amount of release was set at $1.5-7.5 \% L_{0}$. One of the results when the amount of release was $1.5 \% L_{o}\left(L_{o}=12 \mathrm{~mm}\right)$ is shown in Fig. 12. The muscle was released from $L_{o}+0.18 \mathrm{~mm}$ to $L_{o}$ at various times after stimulation. Tension curve, $P$, and shortening curve, $-X$, were recorded simultaneously. The curve connecting a series of peaks of the redeveloped tension after the release gave the tail of the active state. In order to examine the effect of the amount of release on the time course of the active state, various amounts of quick releases, such as $0.3,0.45,0.7$ and $0.9 \mathrm{~mm}$, were also applied. The curves obtained are traced in Fig. 13. Even when the amount of release is as small as $1.5 \% L_{0}$, the experimental curve agrees only approximately but not completely with curve $F$ which is determined by the graphical analysis. As the amount of release increases, 

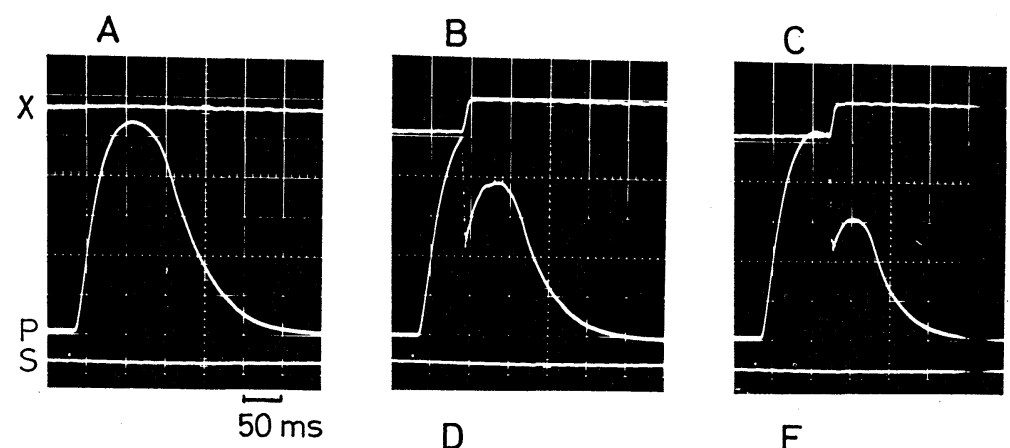

$50 \mathrm{~ms}$

D
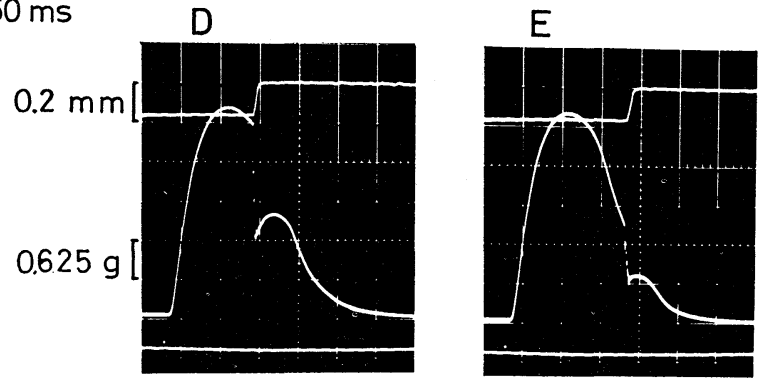

Fig. 12. Changes in tension curve by quick release during isometric twitch. A, isometric twitch; B, released at $62 \mathrm{msec}$; C, $94 \mathrm{msec}$; D, $115 \mathrm{msec}$; E, $160 \mathrm{msec}$ after stimulus; amount of release, $0.18 \mathrm{~mm}\left(1.5 \% L_{o}\right) ; X$, length curve, $0.2 \mathrm{~mm} / \mathrm{div} ; P$, tension curve, $0.625 \mathrm{~g} / \mathrm{div} ; S$, stimulus; sweep, $50 \mathrm{msec} / \mathrm{div} ; P_{o}=5.4 \mathrm{~g} ; L_{o}=12 \mathrm{~mm} ; \mathrm{ms}, \mathrm{msec} ; 10^{\circ} \mathrm{C}$.

the experimental curve decays more quickly, and the duration of the active state decreases, conforming to the observation by BRIDEN and AlPERT (1972). These results suggest that a quick release causes some deactivation of the contractile mechanism and its degree increases with increasing amount of quick release.

b) Quick-stretch method. It is impossible to determine the rising phase of the active state curve by Ritchie's quick-release method. However, applying quick stretches at various times during the rising phase and plotting the troughs of redeveloped tension, the early part of the active state curve can be obtained, because at the trough, as well as at the peak, the contractile component is neither lengthening nor shortening. We applied the quick stretch during the rising phase of the isometric twitch. But it was extremely difficult to observe a measurable trough in tension curve at $10^{\circ} \mathrm{C}$, because the peak time was only $75 \mathrm{msec}$ from the stimulus and the rate of rise of tension was too fast. In order to slow down the tension developement, the muscle was soaked in excess potassium Ringer's solution $([\mathrm{KCl}]=14 \mathrm{~mm})$ and stimulated by $\mathrm{AC}$ at $300 \mathrm{~Hz}$ with linearly increasing voltage, as described by MASHIMA and TsuchiYA (1968). The tension curve thus obtained is curve $P$ in Fig. 14 . The muscle $\left(L_{o}=13 \mathrm{~mm}\right)$ was stretched at constant speed using a velocity controller by $0.21 \mathrm{~mm}\left(1.6 \% L_{o}\right)$ from $L_{o}-0.21 \mathrm{~mm}$ to $L_{o}$. The instance of stretch was $265 \mathrm{msec}$ in $a, 310 \mathrm{msec}$ in $b$ and $325 \mathrm{msec}$ 


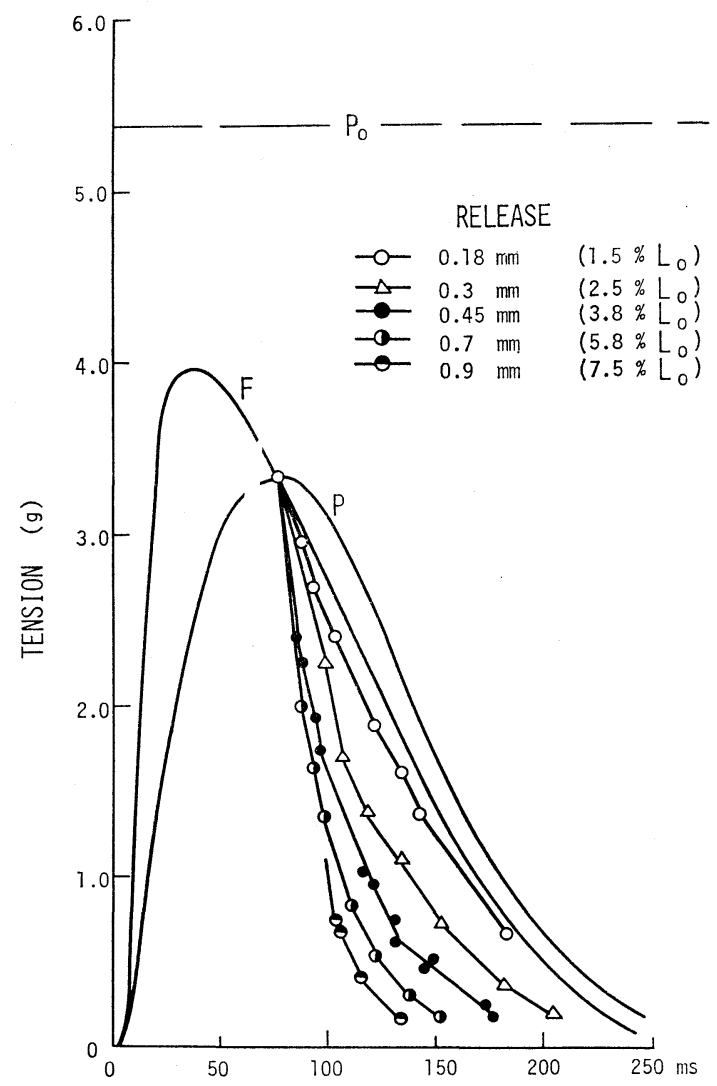

Fig. 13. Effect of the amount of quick release on the falling phase of the active state during isometric twitch. Amount of release is shown in the figure. $P$, tension curve; $F$, active state curve determined by graphical analysis; $P_{o}=5.4 \mathrm{~g} ; L_{o}=12 \mathrm{~mm} ; \mathrm{ms}, \mathrm{msec} ; 10^{\circ} \mathrm{C}$.

in $c$ from the start of stimulation. Immediately after the quick stretch the tension shows a sudden rise and stress relaxation, and then it redevelops, forming a trough. At the bottom of the trough, $P(t)=F(t)$, because $v(t)=0$ and $f(v)=1$ in eqs. (5) and (6). Curve $F_{e}$ in Fig. 14 was obtained by plotting these troughs. Curve $F$ represents the active state curve determined from curve $P$ by graphical analysis. Both curves agree approximately in the rising phase but they differ considerably near the peak. While the difference increases with tension, it is suggested that the contractile component must be activated even by such a small amount of stretch and the degree of activation depends on the contractile force.

When the temperature was lowered to $0^{\circ} \mathrm{C}$, the rate of rise of tension was sufficiently slowed for the application of quick stretch. Therefore, the stretch experiment was repeated at $0^{\circ} \mathrm{C}$ using a single pulse stimulation. One of the results is shown in Fig. 15. The tension, $P$, and muscle length, $X$, are recorded simultaneously. The original record of isometric twitch curve at $L_{o}$ is shown in 

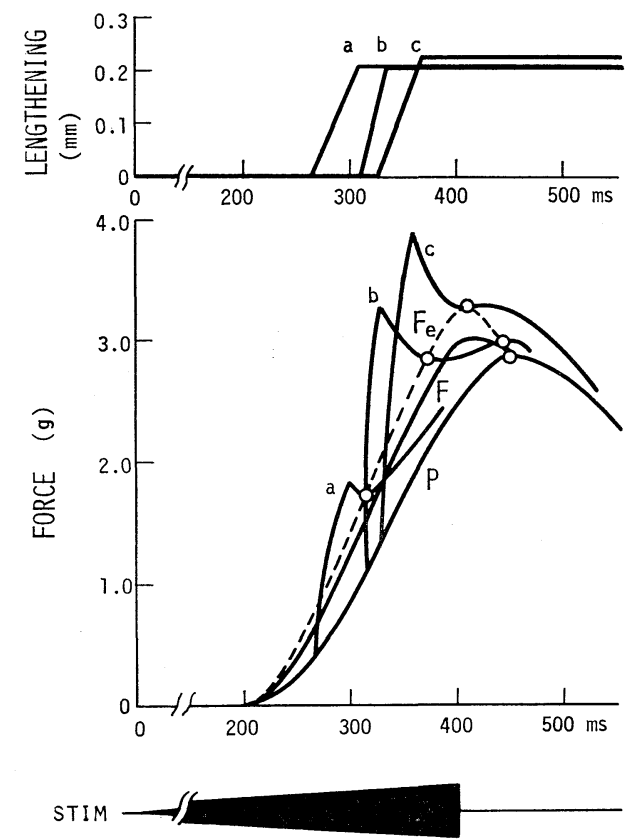

Fig. 14. The rising phase of the active state determined by quick stretch method (open circle). Upper, length curves; Lower, tension curves; $P$, tension curve; $F$, active state curve determined by graphical analysis; $F_{e}$, active state curve determined by quick stretch method; STIM, AC at $300 \mathrm{~Hz}$ with linearly increasing voltage, in the excess potassium solution; time and amount of stretch: a, at $265 \mathrm{msec}$ after the start of stimulation and $0.21 \mathrm{~mm}$; b, at $310 \mathrm{msec}$ and $0.21 \mathrm{~mm}$; c, at $325 \mathrm{msec}$ and $0.22 \mathrm{~mm} ; P_{o}=6.3 \mathrm{~g} ; L_{o}=$ $13 \mathrm{~mm}$; $\mathrm{ms}, \mathrm{msec} ; 10^{\circ} \mathrm{C}$.

A. In B, C and D, the muscle was stretched from $L_{o}-0.25 \mathrm{~mm}$ to $L_{o}\left(L_{o}=14 \mathrm{~mm}\right)$ by $0.25 \mathrm{~mm}$ (about $1.8 \% L_{o}$ ) at 42,55 , and $72 \mathrm{msec}$ after the stimulus, respectively. In Fig. 16, curve $P$ is the trace of tension curve $P$ in Fig. 15. Curve a is the active state curve obtained by plotting the troughs after the stretch. In order to examine the effect of the amount of stretch on the time course of the active state, the amount of stretch was varied to $0.36,0.46$ and $0.57 \mathrm{~mm}$, always keeping the final length at $L_{0}$. Curves b, c and d in Fig. 16 are the active state curves obtained by these experiments. Obviously, as the amount of stretch increases, the active state increases and the rate of rise becomes quicker, that is, the degree of activation caused in the contractile mechanism depends on the amount of quick stretch. But it is confirmed that the active state does not reach its full extent of $P_{o}$ during the isometric twitch even at $0^{\circ} \mathrm{C}$ and even in the muscle activated by the quick stretch of $3.6 \%$ $L_{o}$.

Finally, it is concluded that the analytical method is more favorable than the experimental method for determining the active state curve, because no release 


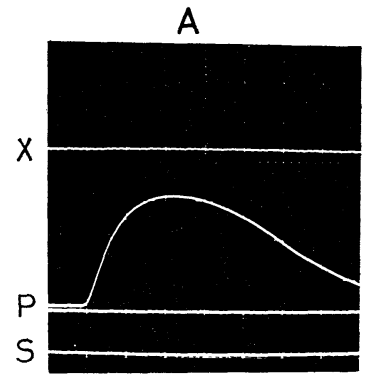

C

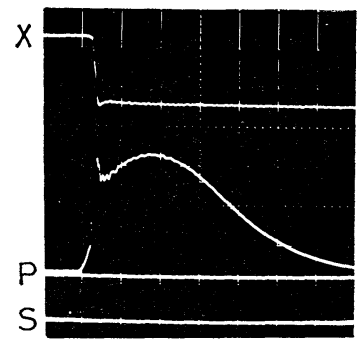

B

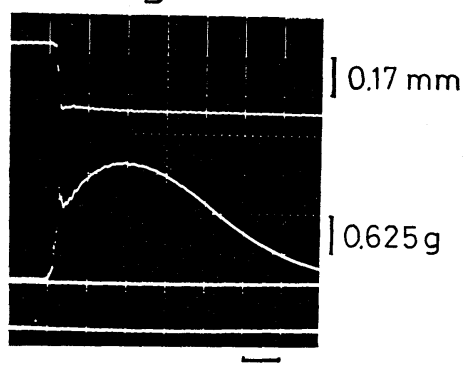

D $100 \mathrm{~ms}$

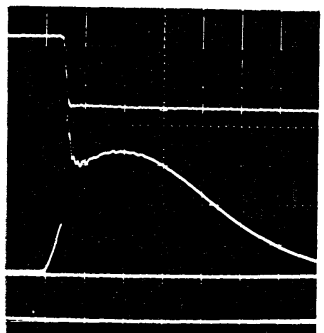

Fig. 15. Changes in tension curve by quick stretch during isometric twitch. A, isometric twitch; B, stretched at $42 \mathrm{msec}$; C, $55 \mathrm{msec} ; \mathrm{D}, 72 \mathrm{msec}$ after stimulus; amount of stretch, $0.25 \mathrm{~mm}\left(1.8 \% L_{o}\right)$, from $L_{o}-0.25 \mathrm{~mm}$ to $L_{o} ; X$, length curve, $0.17 \mathrm{~mm} / \mathrm{div} ; P$, tension curve, $0.625 \mathrm{~g} / \mathrm{div} ; S$, stimulus; sweep, $100 \mathrm{msec} / \mathrm{div} ; P_{o}=2.25 \mathrm{~g} ; L_{o}=14 \mathrm{~mm}$; $\mathrm{ms}, \mathrm{msec} ; 0^{\circ} \mathrm{C}$.

or stretch is applied during the contraction. Only an approximated curve can be obtained by the quick-release or -stretch method, when the amount of release or stretch is less than $2 \%$ of the muscle length.

\section{DISCUSSION}

The material used in the present study was a small bundle preparation obtained from the semitendinosus muscle of the frog. The elastic property of this preparation was quite similar to that of the single fiber examined in the previous paper (MASHIma et al., 1972). Therefore, the results obtained would be comparable with those obtained on a single fiber. And most of the experiments were preformed at $10^{\circ} \mathrm{C}$, because the sarcoplasmic reticulum is ready to release calcium below $10^{\circ} \mathrm{C}$ in caffeinized muscle fiber (SAKAI, 1965) and even in normal muscle fiber a cooling contracture begins to occur below $5^{\circ} \mathrm{C}$ (SAKAI, 1967), although the mechanical measurement after quick release is far easier at $0^{\circ} \mathrm{C}$ than at $10^{\circ} \mathrm{C}$.

The contractile force, $F$, and the load, $P$, were separated and discussed in detail by Mashima et al. (1972). They stated that the difference between $F$ and $P$ was the viscous-like force, $F_{v}$, because when the muscle was released from isometric to isotonic contraction, the force was decreased from $F$ to $P$, as though 


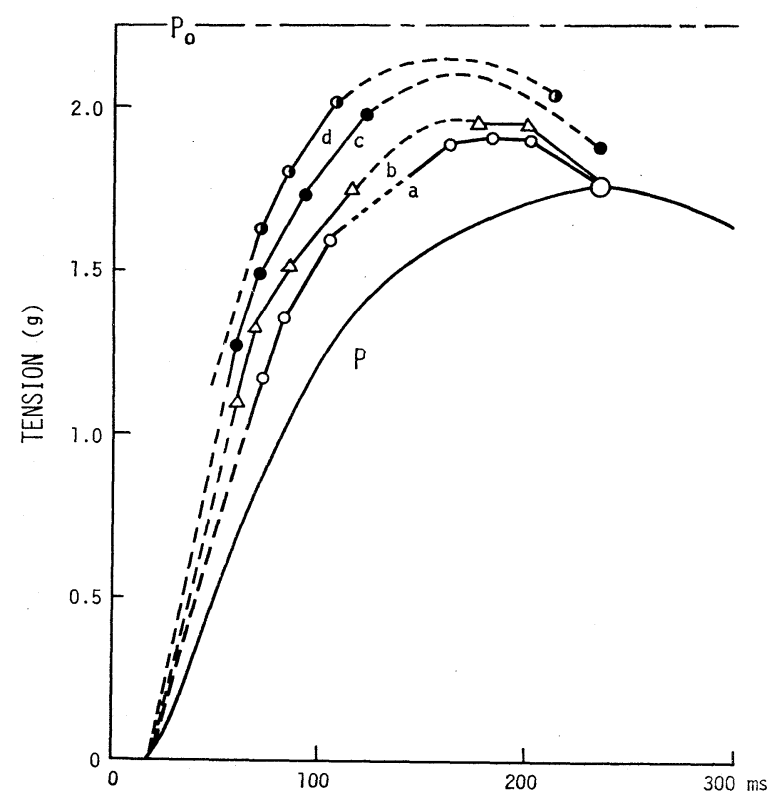

Fig. 16. Effect of the amount of quick stretch on the rising phase of the active state during isometric twitch. Amount of stretch: $a, 0.25 \mathrm{~mm} ; b, 0.36 \mathrm{~mm} ; c, 0.46 \mathrm{~mm} ; d, 0.57 \mathrm{~mm}$; $P$, tension curve; $P_{o}, 2.25 \mathrm{~g} ; L_{o}=14 \mathrm{~mm} ; \mathrm{ms}, \mathrm{msec} ; 0^{\circ} \mathrm{C}$.

there were a viscous-like force, which worked as a function of velocity. The three-component model in the present study was derived from this consideration. The active state curves during both isometric and isotonic contractions were obtained by computer calculation or graphical analysis based on the model by assuming that the force of the force generator in the contractile component, $F(t)$, is nothing but the active state, as proposed by BAHLER et al. (1967). The threecomponent model is not a mere extension of the classical viscoelastic model established by Gasser and HILl (1924) and LeVIN and WyMAN (1927), but a natural conclusion derived from the modern concept of the sliding filament mechanism. The force generator may correspond to a sliding-force generator at the cross-bridge between myofilaments and the viscous-like component may correspond to a mechanism which causes the velocity-dependent tension-loss, dissipating during the sliding of myofilaments.

The analytical method described in the present study is similar to that proposed by BAHLER et al. (1967), but we employed the force-load-velocity relation which fits at any contractile force (at $F \leqq P_{o}$ ), instead of the conventional force-velocity relation which fits only when the contractile force is maintained at the maximum force (at $F=P_{o}$ ). Actually, the contractile force is less than $P_{o}$ during the rising phase or relaxation, probably because some of the cross-bridges are not in active state. The advantages of the analytical method for the determination of the active 
state are as follows: (i) quantitative calculations are possible for the entire course of the active state of isometric and isotonic contractions, (ii) when the tensionextension curve and the force-load-velocity curves of the preparation are known, only the tension curve is needed to determine the active state curve during isometric contraction and no quick release or quick stretch is required, (iii) the active state curve can be obtained simultaneously with the tension and shortening curves, using the operational circuit shown in Fig. 3, (iv) the approximate active state curve during isometric twitch can easily be recorded by means of the simple circuit shown in Fig. 9, which contains only a linear operational amplifier.

Since the study of Hill (1949), the abrupt transition from rest to full activity has generally been accepted in the frog sartorius muscle at $0^{\circ} \mathrm{C}$ and many studies (RITCHIE, 1954; JEWELl and WilKIE, 1960; EdMAN and KIESSLING, 1971) have been done along this line. However, BAHLER et al. (1967) pointed out that the active state does not reach the maximum value of $P_{o}$ but $0.92 P_{o}$ at $17.5^{\circ} \mathrm{C}$ in rat gracilis anticus muscle. Our results showed that the peak intensity of the active state during the isometric twitch reached only $0.7-9.8 P_{o}$ at $10^{\circ} \mathrm{C}$ or $0^{\circ} \mathrm{C}$, and no plateau phase was observed. Two or three stimuli were necessary for the active state to reach its full intensity and form a plateau. The muscle force does not reach its full extent so abruptly but it takes about $40-50 \mathrm{msec}$ at $10^{\circ} \mathrm{C}$. Therefore, the force-velocity relation at $F<P_{o}$ should be applied during this period. EDMAN and KIESSLING (1971) analyzed the rising and falling phases of the active state by applying four shocks and plotting the peaks and troughs of the isometric myogram. From these experiments, however, it is difficult to conclude that the active state reaches its full intensity by a single shock, because the peak or trough produced by the second or later shocks may indicate an intensity of the summated active state, which, of course, reaches the maximum intensity.

According to JEWELL and WILKIE (1958), the active state takes approximately $60 \mathrm{msec}$ to become fully established at $0^{\circ} \mathrm{C}$. Our result was about $40 \mathrm{msec}$ at $10^{\circ} \mathrm{C}$. Taking the temperature difference into account, these results agree rather well. The peak time of $d P / d t$ curve is considerably shorter than the peak time of the active state as seen in Fig. 10A. This would explain the value of $40 \mathrm{msec}$ at $0^{\circ} \mathrm{C}$ obtained by Close (1962). The very rapid rise of the active state reported by EDMAN (1970) may depend not on the initial development of tension but on the development of tension enhanced by previous stimuli.

The rate of rise of the active state increased slightly at the transition from isometric to isotonic contraction. More precise measurement was impossible because of the disturbance caused by mechanical oscillation at the transition, but a quicker rate of rise in the isotonic contraction than in the isometric one was clearly shown in the frog ventricle by MASHIMA and KusHima (1971). This fact suggests that the active cross-bridge requires a higher rate of force development or energy liberation when it moves against the viscous-like force, although the duration of the active state is shortened. 
It was pointed out by JeWELL and WILKIE (1960) that the active state can be determined accurately when the amount of quick release is less than $2 \% L_{0}$. In our results also the active state curve determined by the experimental method is, practically speaking, accurate enough when the amount of release or stretch is less than $2 \% L_{0}$. But as seen in Fig. 16, the intensity of the active state increases with increasing amount of quick stretch almost in proportion to the amount of stretch. According to AвBOTT and AuBERT (1952), if a tetanically stimulated muscle were stretched to a given length it would generate more tension and be able to do more work that during an isometric contraction at that length. RüEGG et al. (1970) observed a transient delayed rise in tension caused by abrupt stretch and suggested that an activation of contractile linkages caused by stretching may account for this tension rise. The measured increase in the active state may be brough about by such activation of cross-bridges, and contractile machinery may have a mechanism to store part of the energy supplied by stretching.

Contrary to this, as seen in Fig. 13, the intensity of the active state obtained by quick release decreases almost proportionally with increasing amount of quick release. Recently, BRIDEN and ALPERT (1972) found that the active state decreased as the extent of shortening or release was increased and for each $0.1 \mathrm{~mm}$ of isotonic shortening there was a $2 \%$ decrease in active state force. From these observations it is apparent that quick release produces a large decrement in the muscle force. As pointed out by RüEGG et al. (1970), a deactivation of the contractile mechanism caused by shortening might account for the decrease in contractile tension after a quick release. And the muscle may have a mechanism to sustain part of the declining energy which is rapidly exhausted by a quick release or even by an active shortening. In order to simulate the change in active state caused by the quick change of length, parallel elasticity within the contractile component must be assumed. Although the physiological meaning of this elasticity is unknown, the presence of an elastic element and another elastic element with viscous as well as elastic properties in the myofilaments has recently been suggested by HuXLEY and Simmons (1971).

The analytical method described in the present study is more favorable than the experimental method for determining the active state, because no release or stretch is applied during the contraction. Of course, the quick release is employed when the tension-extension curve or the force-velocity curve is determined. According to CIVAN and PoDOLSKy (1966), the contractile force reaches a steady value before the velocity becomes steady when the load is changed, and the characteristics of the nonsteady state depend on the change in load and on temperature. But the force-velocity relation is usually measured after the nonsteady period, where the $\mathrm{CC}$ shortens at a constant speed. And the nonsteady period can be shortened when the oscillation in shortening curve is minimized by the device of controlled release. Moreover, JEWELL and WiLkIE (1960) and MASHIMA et al. (1972) verified that the force-velocity relation is applicable any time during 
contraction. With the measurement of tension-extension curve of SEC, it is difficult to separate the shortening immediately after the quick release into passive and active parts, if a part of the instantaneous elasticity resides in the cross-bridges themselves, as suggested by HuxLeY and Simmons (1971). The SEC measured in the present study may involve the instantaneous elasticity of cross-bridges, if any, as well as the noncontractile elasticity. Probably the compliance of SEC which involves a only noncontractile part is slightly smaller than our results shown in Fig. 2. As the experimental evidence, the series elasticity of frog sartorius muscle hardly altered by the change in muscle length (JEwELL and WILKIE, 1958) and the stiffness of SEC of rabbit papillary muscle did not change during both rising and falling phases of contraction (EDMAN and NiLSSON, 1968). Then, it would be better to consider that the SEC involves both passive and active elements, no matter where they exist, as far as they show the instantaneous elasticity, because both of them are lengthened by the force-generating elements as an unseparable component. But further investigation would be necessary about this problem.

\section{REFERENCES}

Aввотt, B. D. and Aubert, X. (1952) The force exterted by active striated muscle during and after change of length. J. Physiol., 177: 77-86.

Bahler, A. S., FAles, J. T., and Zierler, K. L. (1967) The active state of mammalian skeletal muscle. J. Gen. Physiol., 50: 2239-2253.

Briden, K. L. and Alpert, N. R. (1972) The effect of shortening on the time-course of active state decay. J. Gen. Physiol., 60: 202-220.

Civan, M. M. and Podolsky, R. J. (1966) Contraction kinetics of striated muscle fibres following quick changes in load. J. Physiol., 184: 511-534.

Close, R. (1962) The pattern of activation in the sartorius muscle of the frog. J. Gen. Physiol., 46: $1-18$.

Edman, K. A. P. and Nilsson, E. (1968) The mechanical parameters of myocardial contraction studied at a constant length of the contractile element. Acta Physiol. Scand., 72: 205-219.

EDMAN, K. A. P. (1970) The rising phase of the active state in single skeletal muscle fibres of the frog. Acta Physiol. Scand., 79: 167-173.

Edman, K. A. P. and Kiessling, A. (1971) The time course of the active state in relation to sarcomere length and movement studies in single skeletal muscle fibres of the frog. Acta Physiol. Scand., 81: 182-196.

Gasser, H. S. and Hill, A. V. (1924) The dynamics of muscular contraction. Proc. Roy. Soc. $B, 96: 398-437$.

Hill, A. V. (1938) The heat of shortening and the dynamic constants of muscle. Proc. Roy. Soc. B, 126: 136-195.

Hill, A. V. (1949) The abrupt transition from rest to activity in muscle. Proc. Roy. Sco. B, 136: 399-420.

Huxley, A. F. and Simmons, R. M. (1971) Proposed mechanism of force generation in striated muscle. Nature, 233: 533-538.

Jewell, B. R. and WILKIE, D. R. (1958) An analysis of the mechanical components in frog's striated muscle. J. Physiol., 143: 515-543.

JEWell, B. R. and Wilkie, D. R. (1960) The mechanical properties of relaxing muscle. $J$. 
Physiol., 152: 30-47.

Levin, A. and Wyman, J. (1927) The viscous elastic properties of muscle. Proc. Roy. Soc. B, 101: 218-243.

Mashima, H. and Matsumura, M. (1960) On the relation between force and shortening during muscle twitch. Jap. J. Physiol., 10: 602-609.

MAshima, H. and TsuChIYA, H. (1968) Mechanical response generated by alternating current or repetitive square pulses in the frog skeletal muscle. Jap. J. Physiol., 18: 417-431.

Mashima, H. and Kushima, H. (1971) Determination of the active state by the graphical, experimental and instantaneous methods in the frog ventricle. Jap. Heart J., 12: 545-561.

Mashima, H., AKaZawa, K., Kushima, H., and FunI, K. (1972) The force-load-velocity relation and the viscous-like force in the frog skeletal muscle. Jap. J. Physiol., 22: 103-120.

Ritchie, J. M. (1954) The effects of nitrate on the active state of muscle. J. Physiol., 126: $155-168$.

RüEGG, J. C., SteIGer, G. J., and Schadler, M. (1970) Mechanical activation of the contractile system in skeletal muscle. Pflügers Arch., 319: 139-145.

SAKAI, T. (1965) The effects of temperature and caffeine on activation of the contractile mechanism in the striated muscle fibres. Jikei Med. J., 12: 88-102.

SAKAI, T. (1967) Mechanism of contraction-relaxation cycle. Proc. 17th Ann. Meeting of Jap. Med. Assoc., 203-206 (in Japanese).

SANDow, A. (1958) A theory of active state mechanisms in isometric muscular contraction. Science, 127: 760-762.

WiLkIE, D. R. (1950) The relation between force and velocity in human muscle. J. Physiol., 110: $249-280$. 